\title{
Significant barriers to diagnosis and management of adrenal insufficiency in Africa
}

\author{
Thabiso R P Mofokeng', Salem A Beshyah ${ }^{2,3}$, Fazleh Mahomed ${ }^{1}$, Kwazi C Z Ndlovu' ${ }^{1}$ and Ian L Ross ${ }^{4}$ \\ 'Department of Medicine, University of the Free State, Bloemfontein, South Africa \\ 2Department of Medicine, Dubai Medical College, Duabi, United Arab Emirates \\ ${ }^{3}$ Department of Endocrinology, Mediclinic Airport Road Hospital, Abu Dhabi, United Arab Emirates \\ ${ }^{4}$ Division of Endocrinology, Department of Medicine, University of Cape Town, Cape Town, South Africa \\ Correspondence should be addressed to T R P Mofokeng: mofokengtrp@ufs.ac.za
}

\begin{abstract}
Background: The burden and management of primary adrenal insufficiency (PAI) in Africa have not been well documented. We aimed to identify specific disease characteristics, patient demographics, and patterns of clinical management in established PAI in Africa. Methods: An online survey of physicians' experience relating to PAI.

Results: There were 1334 responses received, 589 were complete, and 332 respondents reported managing patients with hypoadrenalism. The described responses were related to a calculated pool of 5787 patients with hypoadrenalism ( 2746 females, 3041 males), of whom 2302 had PAI. The likely causes of PAI in Sub-Saharan Africa (SSA) vs the Middle East and North Africa (MENA) regions included autoimmune disease (20\% vs $60.3 \% ; P<0.001$ ), tuberculosis ( $34 \%$ vs $4.1 \% ; P<0.001$ ), AIDS $(29.8 \%$ vs $1 \% ; P<0.001)$, malignancy, and genetic conditions. Sixteen percent of AD patients (376/2302) presented in an adrenal crisis. Medical emergency identification was not used by $1233(83.6 \%)$ SSA vs $330(40.4 \%)$ MENA patients $(P<0.001)$, respectively. Relative non-availability of diagnostic tests across both regions included adrenal antibodies $63 \%$ vs $69.6 \%$ $(P=0.328)$, s-cortisol $49.4 \%$ vs $26.7 \%(P=0.004)$, s-ACTH $55.7 \%$ vs $53.3 \%(P=0.217)$, and adrenal CT scans $52.4 \%$ vs $31.8 \%(P=0.017)$ in the SSA and MENA region, respectively. Across the entire cohort, the overall hydrocortisone use and extrapolated proportion of synacthen use were $59.4 \%$ and $50.7 \%$, respectively.

Conclusions: Through the perception and practice of healthcare professionals, we identified significant challenges in the diagnosis and management of PAI which may herald high mortality. Differences between regions may reflect the allocation of healthcare resources.
\end{abstract}

\section{Key Words}

- adrenal insufficiency

- hypoadrenalism

- Sub-Saharan Africa

- Middle East and North Africa

- s-cortisol serum cortisol

\section{Introduction}

Primary adrenal insufficiency (PAI) is a rare, potentially fatal, but treatable disease $(1,2)$. The estimated prevalence of PAI in South Africa is three per million (3), in contrast to Western countries in which prevalence estimates vary from 30 per million to 221 per million $(4,5)$. In contrast, the prevalence of PAI in most of Sub-Saharan Africa (SSA) and the Middle East and North African (MENA) countries is largely unknown.
In Western countries, most cases of PAI are caused by autoimmune destruction of the adrenal cortex (6), followed by malignancy, tuberculosis (TB), human immunodeficiency virus (HIV), and genetic causes such as adrenoleukodystrophy (ALD) $(6,7)$. Prevalence data on PAI in SSA have been inferred from case reports and small studies examining adrenal insufficiency in TB patients (8). There is an expectation that the aetiology of PAI in

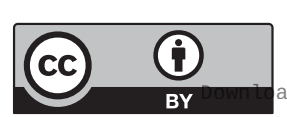

This work is licensed under a Creative Commons Attribution 4.0 International License. 
SSA is considerably influenced by the heavy burden of HIV (9) and TB $(10,11,12)$ in SSA, but this has never been confirmed. In contrast, since the burden of HIV and TB in the MENA region and Europe are low $(13,14)$, PAI attributable to these conditions is likely to be low.

The diagnosis of PAI is often delayed by between 3 and 6 months (15). It is challenging due to the insidious onset of non-specific symptoms such as weakness, fatigue, musculoskeletal pain, weight loss, abdominal pain, depression, and anxiety over months or years (16). Adrenal insufficiency is managed with the combination of glucocorticoids and mineralocorticoids, which are lifesaving. Despite the availability of appropriate replacement therapy in developed countries, there is a residual increased mortality, morbidity, and reduced quality of life $(12)$ associated with PAI $(17,18)$ in the European populations. Morbidity, mortality, quality of life, and availability of replacement therapy in PAI, specifically, in SSA and MENA regions are mostly unknown.

Comprehensive healthcare is not provided for many inhabitants of Africa for a variety of financial and governance challenges, typical of other low and middleincome countries (LMIC) $(19,20,21,22,23)$. The annual government health spending per capita in SSA ranges from $\$ 942$ (South Africa) to $\$ 32$ in (Democratic Republic of Congo) (24), with a median of $\$ 109$ for all African countries (25). In contrast, the proportion of GDP health spent in the MENA region was $4.7 \%$ ( $\$ 403$ per person) (26), with the allocation to healthcare in Saudi Arabia of \$2466 per person in 2014 vs Yemens' \$202 per person (27). Rapid unplanned urbanization exerts pressure on limited resources in SSA, potentially compromising healthcare. Several papers indicate challenges relating to the availability of laboratory tests for PAI $(28,29)$ and imaging diagnostic tests due to financial constraints in Africa $(19,30,31)$. Deficiencies in special investigations may lead to delays in the diagnosis of PAI and treatment with potentially fatal consequences (32).

There is a wide range of doctor to patient ratios in both SSA and the MENA region reflecting different levels of development. The estimated ratios in SSA vary from 1:54,213 in Central Somalia to 1:1639 in South Africa (33), whereas the ratio in MENA is 1.3 per 1000 (26). SSA has the lowest ratings for well-being and the lowest satisfaction with healthcare, compared to the highest scoring nonEnglish-speaking countries of northern Europe (25).

Having recognized the sparse nature of data, we sought to identify challenges in the diagnosis and management of PAI in SSA and MENA region. We attempted to evaluate this through the perceptions and practices of a large sample of physicians in these regions using an online questionnaire. We hypothesized that several barriers will be identified, limiting optimal diagnosis and management. We also hypothesized that, by comparing the SSA to the MENA regions, differences in the diagnosis and management of PAI will be detected, potentially influenced by the level of affluence and the reliance on relatively inexperienced doctors, without the experience of endocrinologists to make a diagnosis of this rare condition.

\section{Methods}

\section{Setting}

This cross-sectional electronic questionnaire-based study was conducted between January and June 2017. For the creation, dissemination, and analysis of the questionnaire, Survey Monkey ${ }^{\circledR}$ (SVMK Inc., San Mateo, CA, USA) was used. The questionnaire was electronically sent to a convenience sample of healthcare professionals primarily residing and practicing in the Middle East and Africa (Supplementary Appendix 1, see section on supplementary materials given at the end of this article). The initial invitation email explained the rationale of the study. Biweekly reminders were sent to enhance the numbers and quality of responses. Repeat submissions from the same internet protocol address were automatically blocked by the survey service. The patients in Africa were identified using a large commercial email database of clinicians in Africa (MedPages, Cape Town, South Africa) and the MENA regions' physicians were identified from a large professional email database held by the investigators. All respondents provided consent before proceeding with the actual survey questions.

\section{Research and ethics}

Approval to conduct this survey was obtained from the University of Cape Town (UCT) Faculty of Health Sciences Human Research and Ethics Committee.

\section{The questionnaire}

The questionnaire sought to establish the grade, rank, and location of the physicians who manage their patients with PAI. We asked respondents to identify whether they practised in rural or urban regions. The respondents were also asked to estimate the number of their patients with PAI, as well as the diagnostic and management problems

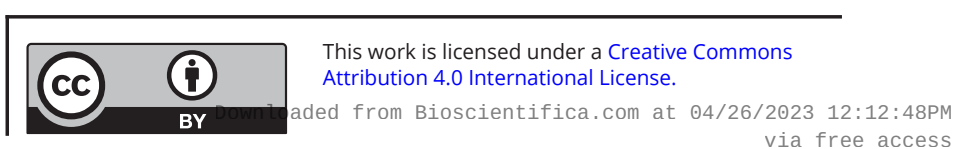


that they encountered at the time of the survey. The questionnaire asked the physicians to report patient demographics, aetiology, presentation, therapy, and to comment on the limitations of diagnosis and treatment of PAI (Supplementary Appendix 2). The final English version was translated into French.

\section{Data analysis}

Two types of data were captured. First, data describing the attributes of the respondents were retrieved directly $(n=332)$. Secondly, data characterizing patients were synthesized based on the numbers of patients seen by a given physician and the relative proportions of the physicians' responses (calculated patients were 5787). However, no direct patients' data were collected. The results were expressed in numbers and adjusted for any missing responses by expression as a percentage of total responses per individual question. Groups were compared using Chi-squared tests or Fisher's exact tests when one of the cell counts was below 5. A two-sample test of proportions was used to compare two proportions of subgroups within variables of the combined cohort. All analyses were performed using STATA statistical software, version 15 (StataCorp, College Station, TX, USA). The level of significance was assigned at $P<0.05$.

\section{Results}

\section{Characteristics of respondents}

A total of 1334 physician responses were received, of whom 589 completed the questionnaire, and of these, 332 respondents confirmed that they, at the time of the survey, manage patients with hypoadrenalism (Supplementary Appendix 1). The respondents were mostly non-endocrine specialists (48.8\%) and primary care doctors (33.3\%) and the minority (17.6\%) were specialist endocrinologists. The proportion who identified themselves as senior doctors in the MENA region was $83.9 \%(47 / 56)$, compared to $62.3 \%(165 / 265)$ in SSA $(P=0.002)$. Regional distribution differed, with $57.1 \%(32 / 56)$ of respondents from MENA self-identified as endocrinologists, compared to $9.8 \%(27 / 275)$ in SSA $(P<0.001)$.

A higher proportion of MENA respondents vs SSA practised in a government clinic $(7.1 \%$ vs $1.1 \%, P=0.017)$ and in hospitals (MENA $42.9 \%$ vs SSA $28.6 \%, P=0.036$ ), respectively. The proportion of private clinical practice was higher in SSA vs the MENA region (28.6\% vs $7.14 \%$, $P<0.001)$. Overall, in this survey, most respondents $87 \%$ practised in cities, but relatively more respondents in SSA $14.5 \%$, compared to MENA $1.8 \%(P=0.006)$ practised in rural regions (Table 1).

Table 1 Professional and practice profiles of medical practitioners (respondents) who participated in survey.

\begin{tabular}{l} 
Attributes \\
\hline Grade (experience) \\
Senior \\
Middle grade \\
Junior \\
Type of practice \\
Government hospital \\
Government clinic \\
Private hospital \\
Private clinic \\
University based \\
Medical speciality \\
Endocrinologist \\
General practitioner \\
Non-endocrine specialist \\
Practice locality \\
Urban \\
Rural
\end{tabular}

\begin{tabular}{c}
\hline SSA $^{\mathbf{a}}(n=276)$ \\
$165(62.3)$ \\
$78(29.4)$ \\
$22(8.3)$ \\
$79(28.6)$ \\
$3(1.1)$ \\
$69(25.0)$ \\
$79(28.6)$ \\
$46(16.7)$ \\
$27(9.8)$ \\
$107(38.9)$ \\
$141(51.3)$ \\
$236(85.5)$ \\
$40(14.5)$ \\
$154(55.8)$ \\
$76(27.5)$ \\
$41(14.9)$ \\
$5(1.81)$
\end{tabular}

\begin{tabular}{c}
\hline MENA $^{\mathbf{a}}(n=56)$ \\
\hline $47(83.9)$ \\
$7(12.5)$ \\
$2(3.6)$ \\
$24(42.9)$ \\
$4(7.1)$ \\
$14(25.0)$ \\
$4(7.14)$ \\
$10(17.9)$ \\
$32(57.1)$ \\
$3(5.4)$ \\
$21(37.5)$ \\
$54(98.2)$ \\
$1(1.8)$ \\
$25(45.4)$ \\
$16(29.1)$ \\
$8(14.6)$ \\
$6(10.9)$
\end{tabular}

\begin{tabular}{r}
\hline -value $^{\mathbf{b}}$ \\
0.002 \\
0.009 \\
0.276 \\
\\
0.036 \\
0.017 \\
1.000 \\
$<0.001$ \\
0.828 \\
\\
$<0.001$ \\
$<0.001$ \\
0.060 \\
\\
\\
0.006 \\
\\
0.160 \\
0.814 \\
0.953 \\
0.004
\end{tabular}

\begin{tabular}{c}
\hline Total $(\%, 95 \% \mathrm{Cl})$ \\
\hline $212(66.0,60.6-71.0)$ \\
$85(26.5,21.9-31.6$ \\
$24(7.5,5.0-10.9)$ \\
$103(31.0,26.2-36.2)$ \\
$7(2.1,1.0-4.4)$ \\
$83(25.0,20.6-30.0)$ \\
$83(25.0,20.6-30.0)$ \\
$56(16.9,13.2-21.3)$ \\
$59(17.8,14.0-22.4)$ \\
$110(33.2,28.3-38.5)$ \\
$162(48.9,43.6-54.3)$ \\
$291(87.6,83.6-90.8)$ \\
$41(12.4,9.2-16.4)$ \\
$179(54.1,48.6-59.4)$ \\
$92(27.8,23.2-32.9)$ \\
$49(14.8,11.4-19.1)$ \\
$11(3.3,1.8-5.9)$ \\
\hline
\end{tabular}

\begin{tabular}{l}
\multicolumn{1}{c}{$\boldsymbol{P}_{\text {-value }}$} \\
Reference \\
$<0.001$ \\
$<0.001$ \\
Reference \\
$<0.001$ \\
0.084 \\
0.084 \\
$<0.001$ \\
\\
Reference \\
$<0.001$ \\
$<0.001$ \\
\\
Reference \\
$<0.001$ \\
\\
Reference \\
$<0.001$ \\
$<0.001$ \\
$<0.001$
\end{tabular}

${ }^{a}$ Data are presented as number (percentage); ${ }^{b} P$-value: comparison between SSA and MENA; ${ }^{c} P$-value: comparison across the entire group of medical practitioners who participated in the survey.

MENA: Middle East and North Africa; SSA: Sub-Saharan Africa.

https://ec.bioscientifica.com

https://doi.org/10.1530/EC-20-0129 (c) 2020 The authors Published by Bioscientifica Ltd

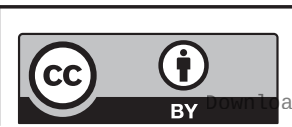

This work is licensed under a Creative Commons Attribution 4.0 International License. ded from Bioscientifica.com at 04/26/2023 12:12:48PM 
When medical practitioners were compared across the entire cohort, there was a preponderance of senior ranked physicians, a predominance of government-employed medical practitioners, the minority were endocrinologists, and a substantial proportion practised in urban vs rural settings. The majority of practitioners had no experience managing an adrenal crisis (Table 1).

\section{Patients characteristics}

The physicians' responses were based on their experiences of 5787 patients with hypoadrenalism. Adrenocorticotropic hormone (ACTH) deficiency disease, long term steroid use, and adrenalectomy accounted for 1275 , 1896, and 314 patients, respectively, and were not included in the analysis of patients with PAI. Of these, the remainder constituted 2302 (39.8\%) patients who had PAI, with 1144 males (49.7\%) and females 1158 (50.3\%). The aetiology of PAI was considered autoimmune in the majority of patients from the MENA region (60.3\%), compared with $20 \%$ in the SSA region, $P<0.001$. While the proportion of PAI attributable to TB in SSA was higher at $34 \%$ compared to $23 \%$ in MENA $(P<0.001)$, similarly, PAI attributable to Acquired Immune Deficiency Syndrome (AIDS) was higher in SSA at $29.8 \%$, compared to $4.1 \%$ in MENA $(P<0.001)$. In the entire group of PAI patients, the aetiology was considered to be TB in 535 (23\%), AIDS 447 (19\%), malignancy 96 (4\%), and genetic causes including ALD 106 (5\%) (Table 2).

Autoimmune conditions associated with PAI in descending order of frequency were primary hypothyroidism 438 (19\%), type 1 diabetes mellitus 332 (14\%), pernicious anaemia $187(8 \%)$, premature ovarian failure 143 (6\%), and Graves' disease 103 (4.5\%). There were relatively fewer patients with type 1 diabetes, but relatively more patients with either premature ovarian failure or pernicious anaemia in the MENA region compared with SSA. Eighty-four percent of patients (1926/2302) presented with a constellation of the classical symptoms of hypoadrenalism most notably abdominal pain, nausea, vomiting, diarrhoea, weight loss, and dizziness. In the MENA region, respondents reported a higher proportion of PAI patients presenting with diarrhoea ( $86 \%$ vs $66.2 \% ; P<0.006)$, abdominal pain $(90.4 \%$ vs $71.2 \% ; P<0.004)$ and dizziness $(92.4 \%$ vs $79.7 \%$; $P<0.029$ ), compared to SSA region, respectively. The proportion of patients presenting in an adrenal crisis was similar in both the MENA and SSA regions (16.4\% vs $16.2 \%$, respectively; $P=0.884$ ). In both geographical regions, a notable proportion of patients (42.6\% up to $69.4 \%$ ) presented with symptoms suggestive of an adrenal crisis (Table 3).

When the clinical characteristics of all the patients were compared, notably the vast majority were within the age group of 16 to 60 years. Aetiologically, PAI was attributed predominantly to autoimmune causes, with the most prevalent association being type 1 diabetes mellitus (Table 2). Notably, nausea was the most common presenting gastrointestinal symptom (81\%; 95\% CI, 76-85\%), compared with the other gastrointestinal features. Non-specific clinical features such as dizziness occurred frequently $(82.0 \%$; 95\% CI, 77.1-86.3\%), and in respect of the criteria for an adrenal crisis, hypoglycaemia (69.4\%; 95\% CI, 63.8-74.6\%) was the most common feature (Table 3).

\section{Diagnostic and management strategies}

For the diagnosis of PAI, depending on access and availability, clinicians relied on at least one of the following methods: clinical grounds only, clinical features in addition to serum sodium and serum potassium only, clinical features and serum sodium and/or serum potassium in addition to relevant antibodies, or clinical features in addition to low serum cortisol with synthetic ACTH (tetracosactide) stimulation tests to varying degrees. A significant proportion of the MENA group physicians 94.4\% (51/54) used serum sodium, cortisol, and synthetic ACTH stimulation tests for the diagnosis, compared to SSA physicians $77.2 \%(183 / 237) P=0.002$ (Table 3). In terms of diagnostic trends across the entire cohort, $80.4 \%$ (95\% CI, 75.4-84.8\%) of practitioners used a combination of clinical features of PAI together with the low serum sodium, serum cortisol, and an ACTH stimulation test to confirm the diagnosis, while 56.2\% (95\% CI, $50.2-62.3 \%)$ of the cohort used clinical features and suggestive biochemistry, without the definitive ACTH stimulation test (Table 4).

\section{Patient management trends}

The proportion of patients using hydrocortisone alone in the MENA region was 34\% (780/828), compared to $28 \%(588 / 1474) ; P<0.001)$ in SSA. Several formulations of glucocorticoid replacement therapy were used, these included hydrocortisone, prednisolone, cortisone acetate, dexamethasone, and betamethasone in decreasing frequency (Table 5). Very low utilization of fludrocortisone use was described overall, but it was significantly lower in the SSA 368 (25\%) vs the MENA 460 (55.6\%); $P<0.001$.

This work is licensed under a Creative Commons Attribution 4.0 International License. ded from Bioscientifica.com at $04 / 26 / 2023$ 12:12:48PM 
Table 2 Reported characteristics of adrenal insufficiency patients under the care of the responding physicians.

\begin{tabular}{|c|c|c|}
\hline Patients' characteristics & $\mathbf{S S A}^{\mathbf{e}}(n=2885)$ & MENA $^{\mathbf{e}}(n=2902)$ \\
\hline \multicolumn{3}{|l|}{ Causes of hypoadrenalism } \\
\hline Bilateral adrenalectomy & $239(8.3)$ & $75(2.6)$ \\
\hline ACTH deficiency disease & $595(20.6)$ & $680(23.4)$ \\
\hline Long term steroid use & $577(20.0)$ & $1319(45.4)$ \\
\hline Primary adrenal insufficiency & $1474(51.1)$ & $828(28.5)$ \\
\hline \multicolumn{3}{|c|}{ Age and sex distribution of primary adrenal insufficiency } \\
\hline Sex (females) ${ }^{a}$ & $779(52.8)$ & $379(45.8)$ \\
\hline Age $0-15$ & $101(6.8)$ & $41(5.0)$ \\
\hline Age $16-60$ & $1235(83.8)$ & $539(65.1)$ \\
\hline Age $>60$ & $138(9.4)$ & $248(30.0)$ \\
\hline \multicolumn{3}{|c|}{ Aetiology of primary adrenal insufficiency ${ }^{b}$} \\
\hline Autoimmune & $294(20.0)$ & $499(60.3)$ \\
\hline Tuberculosis & $501(34.0)$ & $34(4.1)$ \\
\hline ALD and genetic disorders & $74(6.9)$ & $32(3.9)$ \\
\hline AIDS & $439(29.8)$ & $8(1.0)$ \\
\hline Malignancy & $79(5.4)$ & $17(2.1)$ \\
\hline Other & $54(3.7)$ & $22(2.7)$ \\
\hline \multicolumn{3}{|l|}{ Auto immune associations ${ }^{b}$} \\
\hline Type 1 diabetes & $347(23.5)$ & $95(11.5)$ \\
\hline Hypothyroidism & $301(20.4)$ & $137(16.6)$ \\
\hline Graves' disease & $67(4.6)$ & $36(4.4)$ \\
\hline Pernicious anaemia & $123(8.3)$ & $64(7.7)$ \\
\hline Premature ovarian insufficiency & $86(5.8)$ & $57(6.9)$ \\
\hline
\end{tabular}

\begin{tabular}{r} 
P-value $^{\mathbf{f}}$ \\
\hline$<0.001$ \\
0.010 \\
$<0.001$ \\
$<0.001$ \\
\\
0.001 \\
0.069 \\
$<0.001$ \\
$<0.001$ \\
\\
$<0.001$ \\
$<0.001$ \\
0.003 \\
$<0.001$ \\
$<0.001$ \\
0.195 \\
\\
$<0.001$ \\
0.023 \\
0.826 \\
0.604 \\
0.317
\end{tabular}

\begin{tabular}{ccc}
\hline Total $(\%, 95 \% \mathrm{Cl})$ & & P-value $^{\mathrm{g}}$ \\
\cline { 1 - 1 } $314(5.4,4.9-6.0)$ & & $<0.001^{\mathrm{d}}$ \\
$1275(22.0,21.0-23.1)$ & & $<0.001^{d}$ \\
$1896(32.8,31.6-34.0)$ & & $<0.001^{d}$ \\
$2302(39.8,38.5-41.0)$ & & \\
& & \\
$1158(50.3,48.2-52.4)$ & & \\
$142(6.2,5.2-7.2)$ & & $<0.001$ \\
$1774(77.1,75.2-78.8)$ & & Reference \\
$386(16.7,15.3-18.4)$ & & $<0.001$ \\
$793(34.4,32.5-36.4)$ & & Reference \\
$535(23.2,21.5-25.0)$ & $<0.001$ \\
$106(4.6,3.8-5.5)$ & & $<0.001$ \\
$447(19.4,17.8-21.1)$ & $<0.001$ \\
$96(4.2,3.4-18.4)$ & & $<0.001$ \\
$386(16.7,15.3-5.1)$ & & $<0.001$ \\
& & \\
$442(19.2,17.6-20.9)$ & Reference \\
$438(19.0,17.4-20.7)$ & 0.863 \\
$103(4.5,3.7-5.4)$ & $<0.001$ \\
$187(8.1,7.0-9.3)$ & $<0.001$ \\
$143(6.2,5.3-7.3)$ & $<0.001$ \\
\hline & &
\end{tabular}

${ }^{a}$ Gender of patients with hypoadrenalism was declared for 2002 patients in SSA and 2736 in MENA; bPercentages calculated out of patients with Addison's disease ( $n=1474$ for SSA and 828 for MENA); ${ }^{~ P e r c e n t a g e s ~ o f ~ c o m m o n ~ p r e s e n t i n g ~ f e a t u r e s ~ a c c o r d i n g ~ t o ~ r e s p o n d e n t ~ d o c t o r s ~(~} n=276$ for SSA and 56 for MENA); ${ }^{d}$ Secondary hypoadrenalism causes compared to Addison's disease; ${ }^{e}$ Results are expressed as number(percentage); ${ }^{f} P$-value: comparison of clinical characteristics of patients between SSA and MENA; ${ }^{g} P$-value: comparison of all the patients in the entire cohort. AIDS: acquired immunodeficiency syndrome; ALD: adrenoleukodystrophy; MENA: Middle East and North Africa; SSA: Sub-Saharan Africa; TB: Mycobacterium tuberculosis.

Over half of the respondents in both regions, $57.6 \%$ (163/283), used bodyweight for dose adjustment of glucocorticoids. The relative proportions for dose adjustment by weight were $60.8 \%(141 / 232)$ in SSA vs $43.1 \%(22 / 51)$ in MENA $(P=0.021)$, whereas the body surface area-based dose adjustment in SSA was 8.0\% compared to $12.5 \%$ in MENA $(P=0.274)$. The proportion of clinicians using fixed doses in SSA was 72(26.1\%), compared to 22 in the MENA region (39.3\%) $(P=0.046)$ (Table 5).

In cases of emergency, 32.1\% (739/2302) patients were using some form of identification, indicating that they have PAI and need glucocorticoids. Of the 208 patients who used a bracelet, $152(10.3 \%)$ were from SSA vs 56 $(6.8 \%)$ in the MENA region $(P=0.004)$. Of the 531 who used the identification card, SSA had $89(6.0 \%)$ vs 442 $(53.4 \%)$ in the MENA region; $P<0.001$, and 84 patients used other forms of identification.

The clinically significant barriers were mainly related to obtaining replacement therapy in SSA $(47.4 \%, 95 \%$ CI 41.0-54.3\%) vs MENA (33.3\%, 95\% CI 21.0-48.4\%);
$P=0.049$, and unavailable diagnostic testing such as serum cortisol $(49.4 \%$, 95\% CI $42.9-55.8 \%)$ vs $(26.7 \%$, 95\% CI $15.7-41.6 \%) P=0.004$ and adrenal CT $(52.4 \%$, 95\% CI $45.9-58.7 \%)$ vs $(31.8 \%, 95 \%$ CI $19.7-47.1 \%)$ $P=0.017$ in SSA vs MENA, respectively. Across both regions, there was also relative non-availability of serum ACTH and adrenal antibodies (Table 3). The nonavailability of fludrocortisone was reported more often in SSA $63.2 \%$ than in the MENA region $57.4 \%(P=0.008)$. In SSA $34 \%$ of respondents reported language as a barrier to management, compared to $17 \%$ in MENA $(P=0.010)$ (Table 5).

Across the entire cohort, the preferred mode of glucocorticoid replacement was hydrocortisone, followed by cortisone acetate, prednisone, dexamethasone, and betamethasone, in descending order. A significant proportion did not receive fludrocortisone. The vast majority of patients across the cohort did not use any form of identification and most clinicians in this survey reported glucocorticoid dose adjusted for body weight, in contrast to those adjusted for body surface area or fixed-dose.

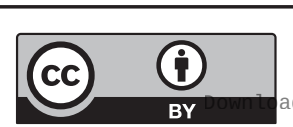

This work is licensed under a Creative Commons Attribution 4.0 International License. ded from Bioscientifica.com at $04 / 26 / 2023$ 12:12:48PM via free access 
Table 3 Reported presenting features and severity of adrenal insufficiency patients under the care of the responding physicians.

\begin{tabular}{|c|c|c|c|}
\hline Patients' characteristics & $\mathbf{S S A}^{\mathbf{a}}(n=2885)$ & MENA $^{\mathbf{a}}(n=2902)$ & P-value ${ }^{b}$ \\
\hline \multicolumn{4}{|l|}{ Presenting features $^{d}$} \\
\hline Gastrointestinal symptoms & $227(82.2)$ & $52(92.9)$ & 0.047 \\
\hline Nausea & $188(79.7)$ & $46(86.8)$ & 0.232 \\
\hline Vomiting & $174(73.7)$ & $43(82.7)$ & 0.175 \\
\hline Diarrhoea & $153(66.2)$ & $43(86.0)$ & 0.006 \\
\hline Abdominal pain & $168(71.2)$ & $47(90.4)$ & 0.004 \\
\hline Anorexia & $164(71.0)$ & $42(80.8)$ & 0.152 \\
\hline \multicolumn{4}{|l|}{ Non-specific features } \\
\hline Dizziness & $188(79.7)$ & $49(92.4)$ & 0.029 \\
\hline Weight loss & $187(77.3)$ & $47(88.7)$ & 0.063 \\
\hline Salt craving & $116(50.7)$ & $30(62.5)$ & 0.135 \\
\hline Skin pigment & $154(65.8)$ & $40(75.5)$ & 0.175 \\
\hline Backache & $115(50.0)$ & $29(56.9)$ & 0.375 \\
\hline Adrenal crisis & $242(16.4)$ & $134(16.2)$ & 0.884 \\
\hline \multicolumn{4}{|c|}{ Features suggestive of adrenal crisis } \\
\hline Hypoglycaemia & $162(67.8)$ & 40 (76.9) & 0.195 \\
\hline Loss of consciousness & $97(42.5)$ & $21(42.9)$ & 0.968 \\
\hline Shock & $127(54.3)$ & $29(55.8)$ & 0.845 \\
\hline
\end{tabular}

\begin{tabular}{ccc}
\cline { 1 - 1 } $279(84.0,79.6-87.8)$ & & \\
$234(81.0,76.0-85.3)$ & & Reference \\
$217(75.3,69.9-80.2)$ & & 0.076 \\
$196(69.7,64.0-75.1)$ & & $<0.001$ \\
$215(74.6,69.2-79.6)$ & & 0.047 \\
$206(72.8,67.2-77.9)$ & & 0.012 \\
& & \\
$237(82.0,77.1-86.3)$ & & Reference \\
$234(79.3,74.2-83.8)$ & & 0.378 \\
$146(52.7,46.6-58.7)$ & & $<0.001$ \\
$194(67.6,61.8-73.0)$ & & $<0.001$ \\
$144(51.3,45.2-57.2)$ & & $<0.001$ \\
$376(16.3,14.8-17.9)$ & & \\
$202(69.4,63.8-74.6)$ & & Reference \\
$118(42.6,36.7-48.6)$ & $<0.001$ \\
$156(54.6,48.6-60.4)$ & $<0.001$ \\
\hline
\end{tabular}

${ }^{a}$ Results are expressed as number (percentage); ${ }^{b} P$-value: comparison of clinical characteristics of patients between SSA and MENA; ${ }^{c} P$-value: comparison

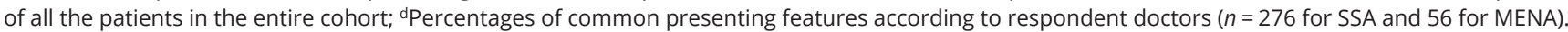

\section{Discussion}

This first Africa and Middle East survey of physicians and their experience in treating patients with PAI revealed significant deficiencies in respect of obtaining critical diagnostic tests necessary for making the diagnosis of PAI. These deficiencies include serum cortisol, serum ACTH, adrenal antibodies, adrenal CT scans and synthetic ACTH stimulation tests in both regions, and replacement therapy, with SSA being more affected than the MENA region. Hydrocortisone was the preferred form of glucocorticoid replacement, but fludrocortisone was not universally prescribed. Dosing adjustments of glucocorticoids were largely made based on body weight, rather than body surface area.

Across the entire cohort, there was a preponderance of senior doctors and a greater urban bias of respondents in this survey. The predominance of senior doctors was more pronounced in the MENA region, suggesting a greater reliance on experienced clinicians for managing this complex disorder, in contrast to SSA, where there was a preponderance of junior doctors. In a trauma emergency study, the group of patients treated by a consultant had a significantly better outcome than the group of patients treated by junior doctors. The analysis of the outcome according to the grade of junior doctors suggested a stepwise improvement in the outcome with seniority in the accident and emergency units, thus supporting that an improved outcome is associated with experience and seniority (34). One could speculate that a preponderance of junior doctors in the SSA region could lead to the diagnosis being missed, with potentially fatal consequences. The under-representation of endocrinologists in the SSA cohort is a deficiency that warrants urgent correction through training.

Clinicians in the SSA identified significant barriers in accessing diagnostic tests, particularly serum cortisol and CT scans of the abdomen. Given the discordant reported synacthen use of $80 \%$, we made a presumptive assessment of the proportion of synacthen use based on the reported serum cortisol availability of $50.7 \%$ across both regions. These results may have been influenced by the respondents' expectation that they should have performed the test. In South Africa, in particular, synacthen is not readily available, and as a non-registered drug, it has to be imported with special permission through the Medicines Control Council (35). It is inferred that, where these special investigations are not widely available, the clinicians in both these regions have to diagnose PAI presumptively, with the result that PAI in SSA and MENA may be under-diagnosed with life-threatening consequences. Significant language barriers must have played a role in suboptimal management of PAI in SSA, compared to the MENA region, considering that for most SSA countries language heterogeneity is the norm (2).

Thesuboptimalmanagement of PAIisalsocompounded by a relatively widespread lack of available medicines such as hydrocortisone (36), and fludrocortisone, which poses https://ec.bioscientifica.com https://doi.org/10.1530/EC-20-0129 (c) 2020 The authors Published by Bioscientifica Ltd

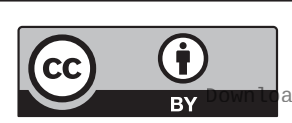

This work is licensed under a Creative Commons Attribution 4.0 International License. ded from Bioscientifica.com at $04 / 26 / 2023$ 12:12:48PM via free access 
Table 4 Reported physicians' practices regarding diagnostic trends of patients with adrenal insufficiency including practitioners' practices and access to diagnostic facilities.

\begin{tabular}{|c|c|c|c|c|c|}
\hline & SSA $^{\mathbf{e}}(n=276)$ & MENA $^{\mathbf{e}}(n=56)$ & P-valuef & Total $(\%, 95 \% \mathrm{Cl})$ & P-valueg \\
\hline \multicolumn{6}{|l|}{ The use of various basis of diagnosis ${ }^{a, b}$} \\
\hline \multicolumn{6}{|l|}{ Clinical features alone } \\
\hline Never used alone & $98(44.6)$ & $23(48.9)$ & \multirow[t]{2}{*}{0.696} & $121(45.4,39.2-51.5)$ & \multirow[t]{2}{*}{0.040} \\
\hline Sometimes/often/always used alone & $121(55.0)$ & $24(51.1)$ & & $145(54.3,48.1-60.4)$ & \\
\hline \multicolumn{6}{|c|}{ Clinical features plus serum sodium combination } \\
\hline Never used these 2 criteria alone & $59(26.3)$ & $18(36.7)$ & \multirow[t]{2}{*}{0.313} & $77(28.2,22.9-33.9)$ & $<0.001$ \\
\hline Sometimes/often/always used & $164(73.2)$ & $31(63.3)$ & & $195(71.4,65.7-76.7)$ & $<0.001^{c}$ \\
\hline \multicolumn{6}{|c|}{ Clinical features plus serum sodium plus serum cortisol combination } \\
\hline Never used these 3 criteria alone & $98(44.0)$ & $20(42.6)$ & \multirow[t]{2}{*}{0.861} & $118(43.7,37.7-49.8)$ & 0.004 \\
\hline Sometimes/often/always used alone & $125(56.0)$ & $27(57.4)$ & & $152(56.2,50.2-62.3)$ & $0.658^{c}$ \\
\hline \multicolumn{6}{|c|}{ Clinical features, low serum sodium plus cortisol plus ACTH test combination } \\
\hline Never used these 4 criteria & $54(22.8)$ & $3(5.6)$ & \multirow[t]{2}{*}{0.002} & $57(19.6,15.2-24.7)$ & $<0.001$ \\
\hline Sometimes/often/always used & $183(77.2)$ & $51(94.4)$ & & $234(80.4,75.4-84.8)$ & $<0.001^{\mathrm{c}}$ \\
\hline \multicolumn{6}{|l|}{ Inadequate diagnostic test availability ${ }^{a, b}$} \\
\hline \multicolumn{6}{|l|}{ Diagnostic tests } \\
\hline Never unavailable & 78 (33.3) & $22(46.8)$ & \multirow[t]{2}{*}{0.210} & $100(35.6,30.0-41.5)$ & \multirow[t]{2}{*}{$<0.001$} \\
\hline Sometimes/often unavailable & $145(62.0)$ & $25(53.2)$ & & $170(60.5,54.5-66.3)$ & \\
\hline \multicolumn{6}{|l|}{ Adrenal antibody } \\
\hline Never unavailable & $53(23.0)$ & $12(26.09)$ & \multirow[t]{2}{*}{0.328} & $65(23.5,18.7-29.0)$ & $<0.001$ \\
\hline Sometimes/often unavailable & $145(63.0)$ & $32(69.6)$ & & $177(64.1,58.2-69.8)$ & $0.381^{d}$ \\
\hline \multicolumn{6}{|l|}{ Serum cortisol } \\
\hline Never unavailable & $108(46.4)$ & $33(73.3)$ & \multirow[t]{2}{*}{0.004} & $141(50.7,44.7-56.7)$ & 0.238 \\
\hline Sometimes/often unavailable & $115(49.4)$ & $12(26.7)$ & & $127(45.7,39.7-51.7)$ & $<0.001^{d}$ \\
\hline \multicolumn{6}{|l|}{ Serum ACTH } \\
\hline Never unavailable & $91(38.7)$ & $21(46.7)$ & \multirow[t]{2}{*}{0.217} & $112(40.0,34.2-46.0)$ & $<0.001$ \\
\hline Sometimes/often unavailable & $131(55.7)$ & $24(53.3)$ & & $155(55.3,49.3-61.3)$ & 0.212 \\
\hline \multicolumn{6}{|l|}{ Adrenal CT scan } \\
\hline Never unavailable & 99 (42.5) & $29(65.9)$ & \multirow[t]{2}{*}{0.017} & $128(46.2,40.2-52.3)$ & 0.494 \\
\hline Sometimes/often unavailable & $122(52.4)$ & $14(31.8)$ & & $136(49.1,43.1-55.1)$ & $0.007^{d}$ \\
\hline
\end{tabular}

a'Often' and 'very often' response combined as 'often'; 'Percentages calculated out of total response given including 'not sure' responses; 'Positive response ('Sometimes/often/always') compared with positive response for use of 'Clinical features' as a basis for diagnosis; ${ }^{d} P o s i t i v e ~ r e s p o n s e$ ('Sometimes/often/always') compared with positive response for non-availability of 'Diagnostic tests'; e'Data are shown as numbers (percentage); ${ }^{f} P$-value: comparison of diagnostic strategies in SSA vs MENA; ${ }^{g} P$-value: comparison of diagnostic strategies across the entire cohort of patients.

ACTH: adrenocorticotropic hormone; MENA: Middle East and North Africa; SSA: Sub-Saharan Africa.

a clear and present danger to patients, particularly in SSA. Since all glucocorticoids are not equivalent, for example, dexamethasone and prednisolone are considerably more potent than hydrocortisone (37), long term use of prednisolone and dexamethasone has been associated with undesirable side-effects such as wakefulness, nocturia, (38), bone mass reduction $(39,40,41)$, hip fractures (42), adverse metabolic health $(43,44)$, and increased mortality (45). Hydrocortisone dose adjustment is thus critical to mitigating these undesirable side-effects, with weight adjustment in adults being the current preferred mode (43), albeit an imperfect method. Current research efforts to approximate the natural cortisol circadian rhythm through chronotherapy (46) hold the future promise of reduction of the observed side-effects.

A significant proportion of PAI in SSA was suggested as being secondary to underlying AIDS and tuberculosis, whereas in the MENA region these conditions were considered relatively infrequent. The likely explanation for this disparity is the background prevalence of HIV in these two settings (47), which is $0.1 \%$ in the MENA region (48), compared to 5\% in SSA (49). Given the lower background prevalence of HIV in the MENA compared with SSA regions, it is likely that the combination of abdominal pain and diarrhoea pointed to the diagnosis of PAI, rather than an infective process or HIV.

Consistent with other reports $(5,50,51)$, autoimmunity was the major cause across both regions and a predominant cause of PAI in the MENA area compared with SSA. The reported autoimmunity of $20 \%$ by the SSA cohort is much lower than was previously found in South Africa, which constituted 50\% of the cohort (52). The low autoimmunity detection might be due to the unavailability of specific auto-antibody testing https://ec.bioscientifica.com

https://doi.org/10.1530/EC-20-0129 (c) 2020 The authors Published by Bioscientifica Ltd

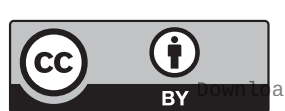

This work is licensed under a Creative Commons Attribution 4.0 International License. ded from Bioscientifica.com at 04/26/2023 12:12:48PM 
Table 5 Reported trends in physicians' practices regarding management of adrenal insufficiency patient and some challenges/ barriers to optimal care.

\begin{tabular}{|c|c|c|c|c|c|}
\hline & $\mathbf{S S A}^{\mathbf{c}}(n=1474)$ & MENA $^{c}(n=828)$ & P-valued $^{d}$ & Total $(\%, 95 \% \mathrm{Cl})$ & $P$-value ${ }^{e}$ \\
\hline \multicolumn{6}{|c|}{ Patterns of glucocorticoid replacement } \\
\hline \multicolumn{6}{|c|}{ Therapeutic drugs used } \\
\hline Hydrocortisone & $588(39.9)$ & $780(94.2)$ & $<0.001$ & $1368(59.4,57.4-61.4)$ & Reference \\
\hline Fludrocortisone & $368(25.0)$ & $460(55.6)$ & $<0.001$ & $828(36.0,34.0-38.0)$ & $<0.001$ \\
\hline Cortisone acetate & $139(9.4)$ & $29(3.5)$ & $<0.001$ & $168(7.3,6.3-8.4)$ & $<0.001$ \\
\hline Prednisone & $442(30.0)$ & $105(12.7)$ & $<0.001$ & $547(23.8,22.0-25.6)$ & $<0.001$ \\
\hline Dexamethasone & $129(8.8)$ & $51(6.2)$ & 0.026 & $180(7.8,6.8-9.0)$ & $<0.001$ \\
\hline Betamethasone & $40(2.7)$ & - & - & $40(1.7,1.2-2.5)$ & $<0.001$ \\
\hline \multicolumn{6}{|c|}{ Method used in drug dose adjustment } \\
\hline Adjusted for body weight & $141(60.8)$ & $22(43.1)$ & 0.0 .021 & $163(57.6,51.6-63.4)$ & Reference \\
\hline Adjusted for body surface area & $22(9.4)$ & 7 (13.7) & 0.349 & $29(10.2,7.0-14.4)$ & $<0.001$ \\
\hline Fixed dose for all patients & $72(31.0)$ & $22(43.1)$ & 0.097 & $94(33.2,27.8-39.0)$ & $<0.001$ \\
\hline \multicolumn{6}{|l|}{ Reported drug non-availability ${ }^{a, b}$} \\
\hline \multicolumn{6}{|l|}{ All medicine } \\
\hline Never unavailable & $111(47.8)$ & $30(66.7)$ & 0.049 & $141(50.9,44.8-56.9)$ & 0.172 \\
\hline Sometimes/often unavailable & $110(47.4)$ & $15(33.3)$ & & $125(45.1,39.2-51.2)$ & \\
\hline \multicolumn{6}{|l|}{ Hydrocortisone } \\
\hline Never unavailable & $150(64.4)$ & $26(56.5)$ & 0.118 & $176(63.1,57.1-68.8)$ & $<0.001$ \\
\hline Sometimes/often unavailable & $72(30.9)$ & $20(43.5)$ & & $92(33.0,27.5-38.8)$ & \\
\hline \multicolumn{6}{|l|}{ Fludrocortisone } \\
\hline Never unavailable & $62(26.5)$ & $20(42.6)$ & 0.008 & $82(29.2,23.9-34.9)$ & $<0.001$ \\
\hline Sometimes/often unavailable & $148(63.2)$ & $27(57.4)$ & & $175(62.2,56.3-68.0)$ & $<0.001^{c}$ \\
\hline \multicolumn{6}{|l|}{ Prednisone } \\
\hline Never unavailable & $186(81.2)$ & $37(82.2)$ & 0.798 & $223(81.4,76.3-85.8)$ & $<0.001$ \\
\hline Sometimes/often unavailable & $31(13.5)$ & $7(15.6)$ & & $38(13.8,10.0-18.5)$ & $<0.001^{\mathrm{c}}$ \\
\hline \multicolumn{6}{|l|}{ Dexamethasone } \\
\hline Never unavailable & $127(55.0)$ & $31(70.4)$ & 0.121 & $158(57.4,51.4-63.4)$ & $<0.001$ \\
\hline Sometimes/often unavailable & $89(39.5)$ & $10(22.7)$ & & $99(36.0,30.3-42.0)$ & $0.458^{c}$ \\
\hline \multicolumn{6}{|l|}{ Betamethasone } \\
\hline Never unavailable & 99 (42.9) & $28(65.1)$ & 0.017 & $127(46.4,40.3-52.4)$ & 0.080 \\
\hline Sometimes/often unavailable & $98(42.4)$ & 9 (20.9) & & $107(39.0,33.2-45.1)$ & $0.142^{c}$ \\
\hline \multicolumn{6}{|l|}{ Additional barriers to management ${ }^{a}$} \\
\hline \multicolumn{6}{|l|}{ Method of patient identification } \\
\hline None & $1233(83.6)$ & $330(40.4)$ & $<0.001$ & $1563(67.9,65.9-69.8)$ & Reference \\
\hline Bracelet & $152(10.3)$ & $56(6.8)$ & 0.004 & $208(9.0,7.9-10.3)$ & $<0.001$ \\
\hline Card & $89(6.0)$ & $442(53.4)$ & $<0.001$ & $531(23.1,21.4-24.8)$ & $<0.001$ \\
\hline \multicolumn{6}{|c|}{ Communication-type barriers to management ${ }^{a}$} \\
\hline Educational level & $110(48)$ & $28(64)$ & 0.161 & $138(50.5,44.4-56.6)$ & Reference \\
\hline Language issues & $79(34)$ & $8(17)$ & 0.010 & $87(31.1,25.8-37.0)$ & $<0.001$ \\
\hline Cultural issues & $91(40)$ & $17(37)$ & 0.154 & $108(39.5,33.7-45.6)$ & 0.010 \\
\hline
\end{tabular}

aPercentages according to respondent doctors ( $n=276$ for SSA and 56 for MENA); 'Percentages calculated out of total responses given including 'not sure' responses; 'Resported responses as Number (\%); ${ }^{2}$-value ${ }^{1}$ : comparison of management strategies in SSA and MENA; ${ }^{e} P$-value ${ }^{2}$ : comparison of all patients' management strategies.

MENA, Middle East and North Africa; SSA, Sub-Saharan Africa.

in SSA, and this could also limit the detection of other autoimmune diseases such as autoimmune polyglandular syndromes (APS) (53). The predominance of females in the MENA region to some degree corroborates autoimmunity as the most important underlying aetiology in this region (54). The significantly higher proportion of patients with type 1 diabetes mellitus and hypothyroidism in SSA may reflect a regional experience or bias in which autoimmunity was a predominant cause of PAI in a largely European population (55).
Across both regions, patients presented with a constellation of symptoms, which was similar including salt craving, anorexia, and vomiting. A higher proportion of patients in the MENA region presented with abdominal pain, diarrhoea, weight loss, and dizziness than those in SSA. In a study on the adrenal crisis, patients reported abdominal pain, vomiting, and diarrhoea among the symptoms which led to the adrenal crisis (56). These symptoms may in the future be used as red flags when training patient and family on how to avoid adrenal

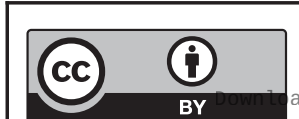

This work is licensed under a Creative Commons Attribution 4.0 International License. 
crises or when to initiate early treatment adjustment. A significant number of patients presented at some stage during their clinical course with an adrenal crisis. Considering the relative predominance of the junior doctors in SSA, it is possible that presenting adrenal crises could either have been missed due to delayed referral to urban centres or non-specific symptoms incorrectly attributable to AIDS by the respondents.

We identified a large proportion of respondents' patients who did not use some form of medical identification, indicating that they have PAI and need steroids in cases of the emergency. The relative proportions in SSA vs MENA, who did not have any form of medical identification, were $83 \%$ and $39 \%$, respectively. In the 1997 North American survey of individuals with PAI, 89.9\% of the patients reported wearing Medic Alert bracelets or necklaces. The low proportion of identification use in SSA may represent a surrogate marker of poor patient disease literacy and can contribute to the mortality associated with an adrenal crisis (57). Although there were no significant differences in the proportion of signs suggestive of adrenal crisis such as hypoglycaemia, shock, and loss of consciousness between the two regions, the proportions of signs were higher than the recorded adrenal crises estimated at $16 \%$ in both regions. This poor correlation between reported adrenal crises at $16 \%$ and signs relating to an adrenal crisis above $40 \%$ in both regions suggest possible under-diagnosis of adrenal crises in both regions, to the possible detriment of patients. Considering that the majority of these respondents in both regions had no experience in managing an adrenal crisis, it is possible that many patients are being missed or do not reach the hospital to receive life-saving treatment. We believe that focused Africa-wide doctor, patient, family, and general population training on adrenal crisis prevention, diagnosis, and treatment is warranted.

We postulate that the discrepancies in the available diagnostic and management options for PAI in SSA regions may be due to the per capita gross domestic product (GDP) health-spend, which in 2014 was \$2466 in Saudi Arabia according to the WHO (27), as opposed to US $\$ 942$ (South Africa) to $\$ 32$ in (Democratic Republic of Congo) (24). Studies have shown that where there are high population densities, there is a tendency toward more physicians per capita (58). This correlates with the urban concentration of physicians in our survey. However, this tendency toward urban concentration detracts from the quality of care in rural settings. This is noteworthy within high per capita health spending countries and even more obvious in low-income countries WHO (27).
The study has strengths and weaknesses that are worth noting: The main limitation stems from the nature of the study being a physicians' survey rather than a patients series. The survey certainly cannot claim to provide a comprehensive picture of the healthcare of patients with PAI in Africa. The model adopted was based on an electronic survey of the physician's perceptions of the burden of disease, its characteristics, and challenges. The online survey saves time and effort and allows a large number of physicians to be involved in such a wide area. From these data, we inferred the status of the healthcare levels and barriers. However, a relatively high number of health professionals widely distributed in the three areas have contributed to the data set providing an African perspective of a rare medical condition, contrasting available data from other continents. The use of English and French in the questionnaires allowed more respondents. However, we observed a suboptimal number of available African countries, with respondents from only 18 out of 54 countries. This is in contrast to ten MENA countries, where all countries were represented. Given the electronic nature of the questionnaire, a possible bias toward urban and technically savvy respondents may exist. With internet connectivity mainly in the urban areas in SSA, there may be under-representation of rural health practitioners. Recall bias may influence the numbers of patients and the circumstances of their management. The study is under-representative to generate information on the approximate prevalence of PAI. Moreover, the specific countries were not evaluated individually. Availability of the synacthen test was not probed with a direct question, which represents an omission; hence, we made a presumptive assessment across both regions.

\section{Conclusion}

This is the first Africa-wide and MENA study of primary adrenal insufficiency, demonstrating that there are substantial barriers to diagnosis and management, and these may likely herald high mortality. Fundamental differences exist between Sub-Saharan Africa and the Middle East and North African regions in the options available with respect to diagnosis and management of PAI, with greater availability as a consequence of better health resource allocation. In particular, as PAI is highly treatable, the education of patients and their healthcare providers is paramount. Unfortunately, the deficiencies in the provision of healthcare are not limited to PAI in these regions, but likely represent gross deficiencies for many conditions and require political will to change the course.

This work is licensed under a Creative Commons Attribution 4.0 International License. ded from Bioscientifica.com at 04/26/2023 12:12:48PM 


\section{Supplementary materials}

This is linked to the online version of the paper at https://doi.org/10.1530/ EC-20-0129.

\section{Declaration of interest}

The authors declare that there is no conflict of interest that could be perceived as prejudicing the impartiality of the research reported.

\section{Funding}

This work did not receive any specific grant from any funding agency in the public, commercial, or not-for-profit sector.

\section{Compliance with ethical principles}

The study was conducted following the ethical principles of the Declaration of Helsinki. Ethical approval was granted by the Faculty of Health Sciences Human Research Ethics Committee, the University of Cape Town, Republic of South Africa (Approval reference HREC/REF: RO42/2016). Informed electronic consent was obtained from all participants before they could proceed to participate in the study.

\section{Author contribution statement}

All the authors contributed to the inception, development, and conduct of the study, including data analysis and drafting and revising of the manuscript for intellectual content. Mofokeng $T R$ P performed questionnaire compilation, data management, analysis, and manuscript development. Beshyah S A performed questionnaire development, data managment, and manuscript development. Mahomed $\mathrm{F}$ performed questionaire development. Ndlovu K C Z performed data management and statistical analysis. Ross I L performed conceptualization, manuscript development, and compiled the survey questionnaire. All authors approved the final version of the manuscript.

\section{Acknowledgements}

The authors are most grateful to all the colleagues who responded to the survey and shared their perceptions and expertise.

\section{References}

1 Husebye ES, Allolio B, Arlt W, Badenhoop K, Bensing S, Betterle C, Falorni A, Gan EH, Hulting AL, Kasperlik-Zaluska A, et al. Consensus statement on the diagnosis, treatment and follow-up of patients with primary adrenal insufficiency. Journal of Internal Medicine 2014275 104-115. (https://doi.org/10.1111/joim.12162)

2 Laitin DD. Language Repertoires and State Construction in Africa. Cambridge, UK: Cambridge University Press, 2007.

3 Ross IL \& Levitt NS. Addison's disease symptoms - a cross sectional study in urban South Africa. PLoS ONE 20138 e53526. (https://doi. org/10.1371/journal.pone.0053526)

4 May M, Vaughn E \& Carey R. Adrenocortical Insufficiency-Clinical Aspects. Adrenal Disorders, pp. 171-189. New York, NY, USA: Thieme Medical Publishers, 1989.

5 Bensing S, Hulting AL, Husebye ES, Kampe O \& Lovas K. MANAGEMENT OF ENDOCRINE DISEASE: Epidemiology, quality of life and complications of primary adrenal insufficiency: a review. European Journal of Endocrinology 2016175 R107-R116. (https://doi. org/10.1530/EJE-15-1242)
6 Oelkers W. Adrenal insufficiency. New England Journal of Medicine 1996335 1206-1212. (https://doi.org/10.1056/ NEJM199610173351607)

7 Laureti S, Vecchi L, Santeusanio F \& Falorni A. Is the prevalence of Addison's disease underestimated? Journal of Clinical Endocrinology and Metabolism 199984 1762. (https://doi.org/10.1210/ jcem.84.5.5677-7)

8 Kibirige D. Endocrine dysfunction among adult patients with tuberculosis: an African experience. Indian Journal of Endocrinology and Metabolism 201418 288-294. (https://doi.org/10.4103/22308210.131136)

9 Ellis ME \& Tayoub F. Adrenal function in tuberculosis. British Journal of Diseases of the Chest 198680 7-12. (https://doi.org/10.1016/00070971(86)90003-3)

10 Barnes DJ, Naraqi S, Temu P \& Turtle JR. Adrenal function in patients with active tuberculosis. Thorax $1989 \mathbf{4 4} 422-424$. (https://doi. org/10.1136/thx.44.5.422)

11 Charmandari E, Nicolaides NC \& Chrousos GP. Adrenal insufficiency. Lancet 2014383 2152-2167. (https://doi.org/10.1016/S01406736(13)61684-0)

12 Grossman A, Johannsson G, Quinkler M \& Zelissen P. Therapy of endocrine disease: perspectives on the management of adrenal insufficiency: clinical insights from across Europe. European Journal of Endocrinology 2013169 R165-R175. (https://doi.org/10.1530/EJE-130450)

13 Gokengin D, Doroudi F, Tohme J, Collins B \& Madani N. HIV/ AIDS: trends in the Middle East and North Africa region. International Journal of Infectious Diseases 201644 66-73. (https://doi. org/10.1016/j.ijid.2015.11.008)

14 Obermeyer CM. HIV in the Middle East. BMJ 2006333 851-854. (https://doi.org/10.1136/bmj.38994.400370.7C)

15 Papierska L \& Rabijewski M. Delay in diagnosis of adrenal insufficiency is a frequent cause of adrenal crisis. International Journal of Endocrinology 20132013 482370. (https://doi. org/10.1155/2013/482370)

16 Bornstein SR, Allolio B, Arlt W, Barthel A, Don-Wauchope A, Hammer GD, Husebye ES, Merke DP, Murad MH, Stratakis CA, et al. Diagnosis and treatment of primary adrenal insufficiency: an Endocrine Society Clinical Practice Guideline. Journal of Clinical Endocrinology and Metabolism 2016101 364-389. (https://doi. org/10.1210/jc.2015-1710)

17 Bergthorsdottir R, Leonsson-Zachrisson M, Odén A \& Johannsson G. Premature mortality in patients with Addison's disease: a populationbased study. Journal of Clinical Endocrinology and Metabolism 200691 4849-4853. (https://doi.org/10.1210/jc.2006-0076)

18 Bancos I, Hazeldine J, Chortis V, Hampson P, Taylor AE, Lord JM \& Arlt W. Primary adrenal insufficiency is associated with impaired natural killer cell function: a potential link to increased mortality. European Journal of Endocrinology 2017176 471-480. (https://doi. org/10.1530/EJE-16-0969)

19 Bonfrer I, van de Poel E, Grimm M \& Van Doorslaer E. Does the distribution of healthcare utilization match needs in Africa? Health Policy and Planning 201429 921-937. (https://doi.org/10.1093/ heapol/czt074)

20 Ciapponi A, Lewin S, Herrera CA, Opiyo N, Pantoja T, Paulsen E, Rada G, Wiysonge CS, Bastías G, Dudley L, et al. Delivery arrangements for health systems in low-income countries: an overview of systematic reviews. Cochrane Database of Systematic Reviews 20179 CD011083. (https://doi.org/10.1002/14651858. CD011083.pub2)

21 Wiysonge CS, Paulsen E, Lewin S, Ciapponi A, Herrera CA, Opiyo N, Pantoja T, Rada G \& Oxman AD. Financial arrangements for health systems in low-income countries: an overview of systematic reviews. Cochrane Database of Systematic Reviews 20179 CD011084. (https:// doi.org/10.1002/14651858.CD011084.pub2) https://ec.bioscientifica.com https://doi.org/10.1530/EC-20-0129 (c) 2020 The authors Published by Bioscientifica Ltd

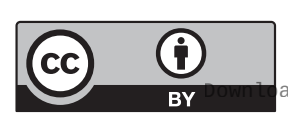

This work is licensed under a Creative Commons Attribution 4.0 International License. ded from Bioscientifica.com at 04/26/2023 12:12:48PM 
22 Kirigia JM \& Barry SP. Health challenges in Africa and the way forward. International Archives of Medicine 20081 27. (https://doi. org/10.1186/1755-7682-1-27)

23 Micah AE, Chen CS, Zlavog BS, Hashimi G, Chapin A \& Dieleman JL. Trends and drivers of government health spending in sub-Saharan Africa, 1995-2015. BMJ Global Health 20194 e001159. (https://doi. org/10.1136/bmigh-2018-001159)

24 Deaton A. Income, health, and well-being around the world: evidence from the Gallup World Poll. Journal of Economic Perspectives 200822 53-72. (https://doi.org/10.1257/jep.22.2.53)

25 Deaton AS \& Tortora R. People in sub-Saharan Africa rate their health and health care among the lowest in the world. Health Affairs 2015 34 519-527. (https://doi.org/10.1377/hlthaff.2014.0798)

26 Hamidi S. Measuring efficiency of governmental hospitals in Palestine using stochastic frontier analysis. Cost Effectiveness and Resource Allocation 201614 3. (https://doi.org/10.1186/s12962-016-0052-5)

27 WHO. World Health Statistics 2016: Monitoring Health for the SDGs Sustainable Development Goals. Geneva, Switzerland: World Health Organization, 2016.

28 Kibirige D, Ssekitoleko R \& Mutebi E. Persistent dizziness and recurrent syncope due to HIV-associated Addison's disease: case report from a resource-limited setting. Southern African Journal of HIV Medicine 201213 150-151. (https://doi.org/10.4102/sajhivmed. v13i3.129)

29 Nassoro DD, Mkhoi ML, Sabi I, Meremo AJ, Lawala PS \& Mwakyula IH. Adrenal insufficiency: a forgotten diagnosis in HIV/AIDS patients in developing countries. International Journal of Endocrinology 20192019 2342857. (https://doi. org/10.1155/2019/2342857)

30 Petti CA, Polage CR, Quinn TC, Ronald AR \& Sande MA. Laboratory medicine in Africa: a barrier to effective health care. Clinical Infectious Diseases 200642 377-382. (https://doi.org/10.1086/499363)

31 Bates I \& Maitland K. Are Laboratory Services Coming of Age in Sub-Saharan Africa? Chicago, IL, USA: The University of Chicago Press, 2006.

32 Rushworth RL \& Torpy DJ. A descriptive study of adrenal crises in adults with adrenal insufficiency: increased risk with age and in those with bacterial infections. BMC Endocrine Disorders 20141479. (https://doi.org/10.1186/1472-6823-14-79)

33 Busia K. Medical provision in Africa - past and present. Phytotherapy Research 200519 919-923.

34 Wyatt JP, Henry J \& Beard D. The association between seniority of accident and emergency doctor and outcome following trauma. Injury 199930 165-168. (https://doi.org/10.1016/s00201383(98)00252-6)

35 South African Health Products Regulatory Authority. Medical device regulations, 2016. Pretoria, South Africa: SAHPRA. (available at: https://www.sahpra.org.za)

36 Husebye ES, Allolio B, Arlt W, Badenhoop K, Bensing S, Betterle C, Falorni A, Gan EH, Hulting AL, Kasperlik-Zaluska A, et al. Consensus statement on the diagnosis, treatment and follow-up of patients with primary adrenal insufficiency. Journal of Internal Medicine 2014275 104-115. (https://doi.org/10.1111/joim.12162)

37 Quinkler M, Beuschlein F, Hahner S, Meyer G, Schöfl C \& Stalla GK. Adrenal cortical insufficiency - a life threatening illness with multiple etiologies. Deutsches Ärzteblatt International 2013110 882-888. (https://doi.org/10.3238/arztebl.2013.0882)

38 Besser GM \& Jeffcoate WJ. Endocrine and metabolic diseases. Adrenal diseases. BMJ 19761 448-451. (https://doi.org/10.1136/ bmj.1.6007.448)

39 Suliman AM, Freaney R, Smith TP, McBrinn Y, Murray B \& McKenna TJ. The impact of different glucocorticoid replacement schedules on bone turnover and insulin sensitivity in patients with adrenal insufficiency. Clinical Endocrinology 200359 380-387. (https://doi.org/10.1046/j.1365-2265.2003.01860.x)
40 Zelissen PM, Croughs RJ, van Rijk PP \& Raymakers JA. Effect of glucocorticoid replacement therapy on bone mineral density in patients with Addison disease. Annals of Internal Medicine 1994120 207-210. (https://doi.org/10.7326/0003-4819-120-3-19940201000005)

41 Løvås K, Gjesdal CG, Christensen M, Wolff AB, Almås B, Svartberg J, Fougner KJ, Syversen U, Bollerslev J, Falch JA, et al. Glucocorticoid replacement therapy and pharmacogenetics in Addison's disease: effects on bone. European Journal of Endocrinology 2009160 993-1002. (https://doi.org/10.1530/EJE-08-0880)

42 Björnsdottir S, Sääf M, Bensing S, Kämpe O, Michaelsson K \& Ludvigsson JF. Risk of hip fracture in Addison's disease: a population-based cohort study. Journal of Internal Medicine 2011270 187-195. (https://doi.org/10.1111/j.1365-2796.2011.02352.x)

43 Løvås K \& Husebye ES. Replacement therapy for Addison's disease: recent developments. Expert Opinion on Investigational Drugs 200817 497-509. (https://doi.org/10.1517/13543784.17.4.497)

44 Forss M, Batcheller G, Skrtic S \& Johannsson G. Current practice of glucocorticoid replacement therapy and patient-perceived health outcomes in adrenal insufficiency-a worldwide patient survey. BMC Endocrine Disorders 201212 8. (https://doi.org/10.1186/1472-6823$12-8)$

45 Johannsson G, Falorni A, Skrtic S, Lennernäs H, Quinkler M, Monson JP \& Stewart PM. Adrenal insufficiency: review of clinical outcomes with current glucocorticoid replacement therapy. Clinical Endocrinology 201582 2-11. (https://doi.org/10.1111/cen.12603)

46 Oprea A, Bonnet NCG, Polle O \& Lysy PA. Novel insights into glucocorticoid replacement therapy for pediatric and adult adrenal insufficiency. Therapeutic Advances in Endocrinology and Metabolism 2019102042018818821294 . (https://doi. org/10.1177/2042018818821294)

47 Lopez AD, Mathers CD, Ezzati M, Jamison DT \& Murray CJ. Global and regional burden of disease and risk factors, 2001: systematic analysis of population health data. Lancet 2006367 1747-1757. (https://doi.org/10.1016/S0140-6736(06)68770-9)

48 Gökengin D, Doroudi F, Tohme J, Collins B \& Madani N. HIV/ AIDS: trends in the Middle East and North Africa region. International Journal of Infectious Diseases 201644 66-73. (https://doi. org/10.1016/j.ijid.2015.11.008)

49 Hontelez JA, de Vlas SJ, Baltussen R, Newell ML, Bakker R, Tanser F, Lurie M \& Bärnighausen T. The impact of antiretroviral treatment on the age composition of the HIV epidemic in sub-Saharan Africa. AIDS 201226 (Supplement 1) S19-S30. (https://doi.org/10.1097/ QAD.0b013e3283558526)

50 Zelissen PM, Bast EJ \& Croughs RJ. Associated autoimmunity in Addison's disease. Journal of Autoimmunity 19958 121-130. (https:// doi.org/10.1006/jaut.1995.0009)

51 Betterle C \& Morlin L. Autoimmune Addison's disease. Endocrine Development 201120 161-172. (https://doi. org/10.1159/000321239)

52 Ross I \& Levitt N. Diagnosis and management of Addison's disease: insights gained from a large South African cohort. Journal of Endocrinology, Metabolism and Diabetes of South Africa 201116 86-92. (https://doi.org/10.1080/22201009.2011.10872256)

53 Ross IL, Levitt NS, Schatz DA \& Johannsson G. Ethnicity influences the diagnosis of primary adrenal insufficiency. Clinical Endocrinology 201378 800-802. (https://doi.org/10.1111/cen.12063)

54 Al-Jurayyan N. Primary adrenal insufficiency (PAI): a major teaching hospital experience, Riyadh, Saudi Arabia. International Journal of Clinical Therapeutics and Diagnosis 20153 92-94.

55 Ross I, Boulle A, Soule S, Levitt N, Pirie F, Karlsson A, Mienie J, Yang $\mathrm{P}$, Wang $\mathrm{H}$, She JX, et al. Autoimmunity predominates in a large South African cohort with Addison's disease of mainly European descent despite long-standing disease and is associated with HLA https://ec.bioscientifica.com https://doi.org/10.1530/EC-20-0129
This work is licensed under a Creative Commons Attribution 4.0 International License. ded from Bioscientifica com at $04 / 26 / 2023$ 12:12:48PM 
DQB ${ }^{*} 0201$. Clinical Endocrinology 201073 291-298. (https://doi. org/10.1111/j.1365-2265.2010.03807.x)

56 White K \& Arlt W. Adrenal crisis in treated Addison's disease: a predictable but under-managed event. European Journal of Endocrinology 2010162 115-120. (https://doi.org/10.1530/EJE-09-0559)

57 Regan EA, Vaidya A, Margulies PL, Make BJ, Lowe KE \& Crapo JD. Primary adrenal insufficiency in the United States: diagnostic error and patient satisfaction with treatment. Diagnosis 20196 343-350. (https://doi.org/10.1515/dx-2019-0013)

58 Cooper RA. States with more physicians have better-quality health care: at the state level, increased numbers of both family physicians and specialists per capita are associated with higher quality of health care. Health Affairs 200827 (Supplement1) w91-w102. (https://doi. org/10.1377/hlthaff.28.1.w91)

Received in final form 27 March 2020

Accepted 28 April 2020

Accepted Manuscript published online 28 April 2020

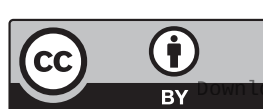

This work is licensed under a Creative Commons Attribution 4.0 International License.

ded from Bioscientifica.com at 04/26/2023 12:12:48PM via free access 